\title{
Media and strain studies for the scaled production of cis-enone resorcylic acid lactones as feedstocks for semisynthesis
}

\author{
Zeinab Y. Al Subeh $\mathbb{D}^{1} \cdot$ Huzefa A. Raja ${ }^{1} \cdot$ Jennifer C. Obike ${ }^{1} \cdot$ Cedric J. Pearce $\mathbb{C}^{2} \cdot$ Mitchell P. Croatt $^{1} \cdot$ \\ Nicholas H. Oberlies (iD)
}

Received: 20 April 2021 / Revised: 1 June 2021 / Accepted: 7 June 2021 / Published online: 21 June 2021

(c) The Author(s) 2021. This article is published with open access

\begin{abstract}
Resorcylic acid lactones (RALs) with a cis-enone moiety, represented by hypothemycin (1) and (5Z)-7-oxozeaenol (2), are fungal secondary metabolites with irreversible inhibitory activity against protein kinases, with particularly selective activity for inhibition of TAK1 (transforming growth factor beta-activated kinase 1). Gram-scale quantities of these compounds were needed as feedstock for semi-synthesizing RAL-analogues in a step-economical fashion. To do so, this study had three primary goals: identifying fungi that biosynthesized $\mathbf{1}$ and $\mathbf{2}$, enhancing their production by optimizing the fermentation conditions on the lab scale, and developing straight forward purification processes. After evaluating 536 fungal extracts via an in-house dereplication protocol, three strains were identified as producing cis-enone RALs (i.e., MSX78495, MSX63935, MSX45109). Screening these fungal strains on three grain-based media revealed enhanced production of $\mathbf{1}$ by strain MSX78495 on oatmeal medium, while rice medium increased the biosynthesis of $\mathbf{2}$ by strain MSX63935. Furthermore, the purification processes were improved, moving away from HPLC purification to utilizing two to four cycles of resuspension and centrifugation in small volumes of organic solvents, generating gram-scale quantities of these metabolites readily. In addition, studying the chemistry profiles of strains MSX78495 and MSX63935 resulted in the isolation of ten other RALs (3-12), two radicinin analogues (13-14), and six benzopyranones (15-20), with 19 and 20 being newly described chlorinated benzopyranones.
\end{abstract}

\section{Introduction}

The fungal kingdom, which is estimated to include between 2.2 and 5.1 million species represents a large reservoir for a variety of bioactive compounds $[1,2]$. It is well known that growth conditions and fermentation media have a significant impact on the fungal biosynthetic machinery [3]. Both the yield and the composition of fungal secondary metabolites are affected by environmental factors [4-10]. The "One-Strain-Many Compounds" approach (OSMAC)

Supplementary information The online version contains supplementary material available at https://doi.org/10.1038/s41429021-00432-3.

Nicholas H. Oberlies

nicholas_oberlies@uncg.edu

1 Department of Chemistry and Biochemistry, The University of North Carolina at Greensboro, Greensboro, NC, USA

2 Mycosynthetix, Inc., Hillsborough, NC, USA was popularized by Bode et al. [11] as a powerful strategy to increase the number of secondary metabolites available from one microbial source, and this involves the alteration of easily accessible cultivation parameters, i.e., media composition. For example, we have recently used the OSMAC approach to produce verticillins as a feedstock for the generation of semisynthetic analogues $[6,12]$.

Resorcylic acid lactones (RALs) are a class of fungal macrolactone polyketides that have received significant attention due to a wide range of pharmacological properties, including antibiotic, antifungal, antimalarial, antiparasitic, antiviral, anabolic, cytotoxic, estrogenic, immunosuppressive, nematocidal, and sedative activities [13-16]. More specifically, interest in RALs has increased since the discovery of their potent inhibitory activity against several oncogenic protein kinases [17]. In particular, cis-enone containing RALs, represented by hypothemycin (1) and (5Z)-7-oxozeaenol (2), act as irreversible inhibitors of a select few protein kinases by forming stable Michael addition products with cysteine residues in the ATP-binding pocket $[18,19]$. Given the vital role of protein kinases in 
the development, progression, and aggressiveness of cancer [20], these natural products have promise as anticancer drug leads. Accordingly, we and others [21-25] have probed analogues of hypothemycin (1) and (5Z)-7-oxozeaenol (2) for their kinase inhibitory activities.

A goal of the current study was to leverage our experience in natural products chemistry with expertise in synthetic chemistry [21, 26-28]. Building from our knowledge of mycology and fungal metabolites, we strove to develop methods to generate the RALs on a scale that facilitates synthetic chemistry efforts. We have previously characterized a suite of RALs from various fungal species, such as Halenospora sp., Phoma sp., and Setophoma sp. [29-31]. For example, (5Z)-7-oxozeaenol and its derivatives were isolated from a Phoma sp. (now identified as Setophoma sp., strain MSX63935) and evaluated for effects on cancer cells [30, 32, 33]. Using those RALs as starting materials, seven semisynthetic analogues of (5Z)-7-oxozeaenol were synthetized and investigated for transforming growth factor beta-activated kinase 1 (TAK1)-inhibitory activities, where the novel nonaromatic difluoro-derivative of (5Z)-7-oxozeaenol inhibited TAK1 at the nanomolar level [21].

The development of cis-enone RAL analogues that retain TAK1 inhibitory activity can be achieved through two main pathways: total synthesis from simple starting materials or semisynthesis via altering the compounds isolated from nature. While total synthesis of a variety of RALs has been disclosed [14], total synthesis of cis-enone RALs is often challenged by the high number of the reactions involved, the low overall yields, and the need to install the cis-enone at a late stage to avoid isomerization to the more stable trans-isomer [34,35], which lacks activity against TAK1 [21]. Comparatively, it is attractive to use the naturally occurring cis-enone RALs as starting points to perform chemical modifications. This semisynthetic approach could facilitate the generation of a large number of analogues in very few synthetic operations, i.e., a more step-economical approach [36-40]. Semisynthesis is not without its own set of challenges, and the limited supply of the naturally occurring RALs is paramount, as evidenced by the high cost of the two main cis-enone RALs (e.g., $\$ 569$ for $1 \mathrm{mg}$ of 1 and $\$ 185$ for $1 \mathrm{mg}$ of 2 from SigmaAldrich) [41]. Thus, the generation of gram-scale quantities of $\mathbf{1}$ and $\mathbf{2}$ was approached via three interrelated goals. First, fungi known to biosynthesize cis-enone RALs were identified. Next, the fermentation conditions were probed, with the goal of developing cost-efficient methods that could be implemented on the gram-scale. Finally, the techniques to purify $\mathbf{1}$ and $\mathbf{2}$ from fungal extracts were optimized. In addition, a benefit of scaling up the fermentation procedures was the identification of new compounds that are minor constituents.

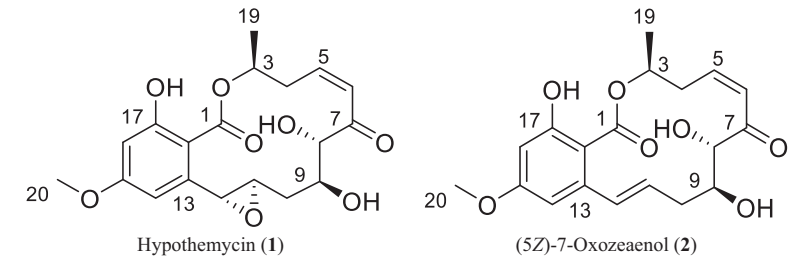

Fig. 1 Structures of hypothemycin (1) and (5Z)-7-oxozeaenol (2)

\section{Results and discussion}

\section{Identifying fungal strains that biosynthesize cis- enone RALs}

Over the past decade, our research team has built an inhouse library of secondary metabolites isolated from filamentous fungi $[42,43]$. This database, which includes over 625 compounds, is used to probe the metabolite profile of fungal extracts, and to date, at least 536 fungal cultures have been screened with our dereplication protocol. Among these, seven fungal strains were identified as biosynthesizing RALs (data not shown), and three of those produced cisenone RALs (i.e., hypothemycin (1) and (5Z)-7-oxozeaenol (2)) (Fig. 1 and S1). Accordingly, fungal strains MSX78495, MSX63935, and MSX45109 were chosen to investigate their potential for yielding gram-scale amounts of $\mathbf{1}$ and 2. Interestingly, while two of the strains (i.e., MSX78495 and MSX63935) produced both compounds, strain MSX45109 seemed to only generate 1, albeit at a very low level (Fig. S1).

\section{Media studies to enhance the production of cis-enone RALs}

To enhance the production of hypothemycin (1) and (5Z)-7oxozeaenol (2) on the gram- scale, solid-state fermentation cultures of the three cis-enone RAL-producing fungi were examined on rice, oatmeal, and Cheerios (Figs. S2 and S3), due to previous experience with these media as a starting point for enhanced biosynthesis of fungal metabolites $[4,6]$; each of those conditions were studied as biological triplicates. While we have employed scores of other media, both defined and rich, we find that these three are a cost effective way to begin the process, turning to other media only if necessary [9]. Subsequently, the cultures were extracted and subjected to UPLC-HRESIMS to confirm the production of the targeted compounds (i.e., $\mathbf{1}$ and/or 2), to measure their relative abundance among the various growth conditions, and to determine the preferred fungal strain and culture medium for the highest yields (Figs. S4 and S5).

Based on the UPLC-HRESIMS chromatograms (Fig. S5), hypothemycin (1) was detected in the extracts of strains 


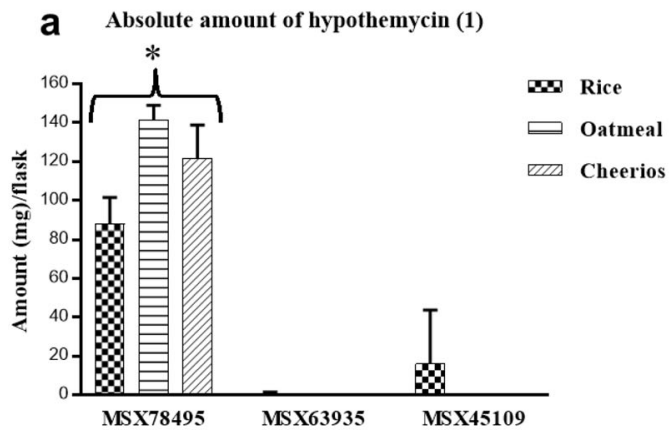

Fig. 2 a, b show the absolute amounts of hypothemycin (1) and (5Z)7-oxozeaenol (2), respectively, across cultures grown on rice, oatmeal, and Cheerios media. An asterisk Indicates significantly higher productions of hypothemycin (1) by strain MSX78495 in panel (a) or (5Z)-7-oxozeaenol (2) by strain MSX63935 in panel (b), compared to

MSX78495, MSX63935, and MSX45109, while (5Z)-7oxozeaenol (2) was detected only in the former two strains (Fig. 2). Since the growth medium is known to affect the secondary metabolite profile of fungal cultures [3], the relative abundance of both $\mathbf{1}$ and $\mathbf{2}$ were measured across the three strains and three different culture media (Fig. S6). For 1, strain MSX78495 showed the highest production, with oatmeal delivering the most robust results, relative to rice and Cheerios (Fig. S6). Interestingly, while $\mathbf{1}$ could be detected under at least one growth condition for all three strains (Fig. S5), the biosynthesis by strain MSX78495 was far superior Fig. S6). On the other hand, the highest biosynthesis of $\mathbf{2}$ was observed with fungal strain MSX63935 fermented on rice medium (Fig. S6). In contrast to each other, strain MSX78495 biosynthesized 1 on all three media, with a preference for oatmeal, whereas with strain MSX63935, the production of $\mathbf{2}$ was by far the best on rice medium, with nearly zero production when fermenting with Cheerios. Studies are warranted to investigate how the biosynthesis of two structurally-related compounds could be so different. During our study, one of the three biological replicates of strain MSX63935 grown on rice medium did not show optimal growth as compared to the other two cultures. This caused the manifestation of large error bars in Figs. S6b and $2 b$ for the relative and absolute amount of $\mathbf{2}$ from strain MSX63935 (Fig. S4). Thus, this culture was excluded from all further isolation and purification processes discussed below.

The absolute amounts of $\mathbf{1}$ and $\mathbf{2}$ among the various extracts were measured by developing calibration curves for these two RALs (Fig. S7 and Table S3). Accordingly, the amount of 1 produced by the fungal strain MSX78495 was $87.9 \pm 13.6 \mathrm{mg} /$ flask, $141.3 \pm 7.8 \mathrm{mg} /$ flask, and $121.8 \pm$ $17.0 \mathrm{mg} /$ flask using rice $(10 \mathrm{~g} /$ flask $)$, oatmeal $(10 \mathrm{~g} /$ flask $)$, and Cheerios ( $7 \mathrm{~g} /$ flask) media, respectively (Fig. 2a). Strain MSX78495 was a superb producer of $\mathbf{1}$, with a slight, although not statistically significant, preference for oatmeal

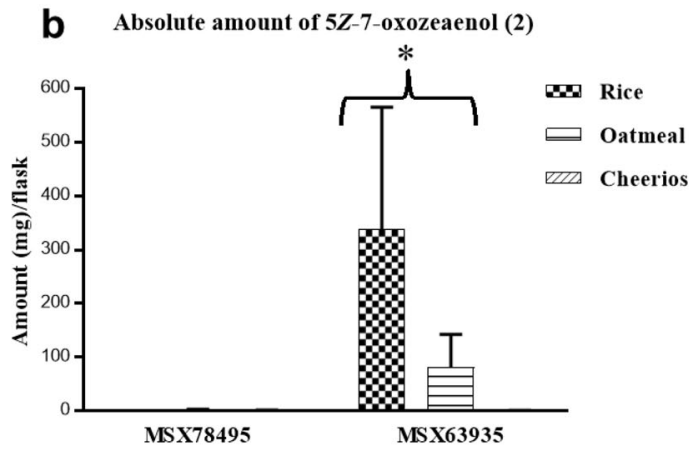

other fungal strains $(p<0.05)$ as demonstrated in Tables S1 and S2. Data are presented as mean \pm SD. One of the three biological replicates of strain MSX63935 on rice medium did not show optimal growth, which caused the large error bars in (b) for the absolute amount of 2 from strain MSX63935 grown on rice

media. Growing fungal strain MSX63935 on rice allowed for the production of $337.9 \pm 227.9 \mathrm{mg}$ per flask of (5Z)-7oxozeaenol (2) as compared to $80.0 \pm 61.8 \mathrm{mg}$ per flask of oatmeal medium (Fig. 2b). While the error bars for these latter measurements were somewhat large (Fig. 2b), the general trend was approximately a fourfold improvement in biosynthesis of $\mathbf{2}$ when fermenting strain MSX63935 on rice vs. oatmeal.

\section{Improved procedures for the isolation and purification of hypothemycin}

With enhanced fermentation procedures in hand via strain MSX78495, we sought to next optimize the isolation and purification of $\mathbf{1}$. To do so, the extracts obtained from strain MSX78495 grown on the three different culture media were combined and subjected to a first round of fractionation via normal phase flash chromatography to obtain six fractions (Fig. 3 and S8). The fourth fraction $(643 \mathrm{mg}$ ) was found to be over $97 \%$ pure hypothemycin (1) as noted by ${ }^{1} \mathrm{H}$ NMR and UPLC-PDA data (Fig. S9). In addition, the adjacent fraction (i.e., fraction 3; $650 \mathrm{mg}$ ) was $\sim 68 \% 1$ as indicated by analogous ${ }^{1} \mathrm{H}$ NMR and UPLC-PDA data (Fig. S10). To further purify fraction 3 , a second round of flash chromatography was performed using nearly identical procedures (data not shown) to obtain a fraction $(\sim 500 \mathrm{mg})$ that was enriched in 1( $\sim 89 \%$ pure). This sample was subjected to two cycles of resuspension in small volumes of HPLCgrade $\mathrm{MeOH}(6 \mathrm{ml}$ for the 1 st cycle and $3 \mathrm{ml}$ for the $2 \mathrm{nd}$ cycle) followed each time by centrifugation for $5 \mathrm{~min}$ at 14000 RPM (g force of $~ 15340$ ) to yield a pelleted sample of 1 ( $>94 \%$ pure; $400 \mathrm{mg}$; Fig. S11). The supernatants from the $1 \mathrm{st}$ and the 2 nd cycle of centrifugations were collected (64 mg and $33 \mathrm{mg}$, respectively), and their ${ }^{1} \mathrm{H}$ NMR spectra were compared to that of the precipitate (Fig. S12). While hypothemycin (1) was a major component in the supernatant samples, most of the impurities and/or other 
Fig. 3 Illustration of the isolation and purification protocol of hypothemycin (1), showing how $\mathbf{1}$ can be generated both from a column fraction and via centrifugation. Over a gram of $\mathbf{1}$ was generated from nine flasks: three fermented on rice, three fermented on oatmeal, and three fermented on Cheerios. We predict that the yield would be even higher by $\sim 20 \%$ if all nine flasks were grown on oatmeal
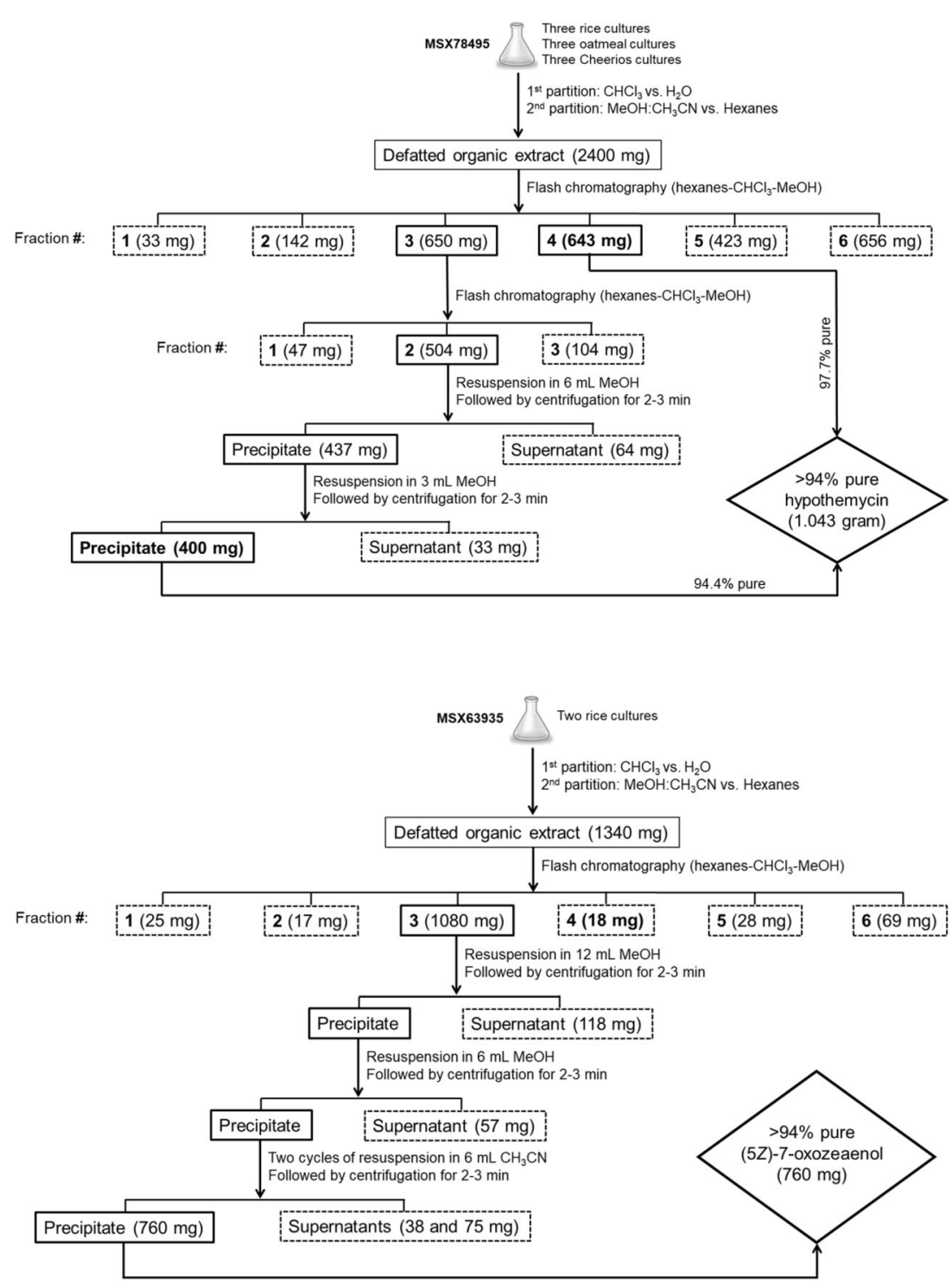

Fig. 4 Illustration of the isolation and purification protocol of (5Z)-7-oxozeaenol (2), showing how 2 can be generated both from a column fraction and via centrifugation. As $760 \mathrm{mg}$ of 2 were generated from two flasks fermented on rice, we predict that over a gram of $\mathbf{2}$ could be generated with this procedure from three flasks of strain MSX63935 grown on rice investigating the three biological replicates grown on rice, the second culture did not grow well as evidenced by a lower amount of extract, and thus less of 2, as compared to the other two cultures (Fig. S4). While this resulted in a large error bar, we felt it was important to be transparent about this fact. Accordingly, the spurious extract was excluded from the purification process. The other two extracts were combined and subjected to flash chromatography to obtain $1080 \mathrm{mg}$ of the third fraction (Fig. 4 and S13), which was enriched for (5Z)-7-oxozeaenol (2) as noted in the ${ }^{1} \mathrm{H}$ NMR spectrum and UPLC-PDA chromatogram (Fig. S14; $\sim 68 \%$ 2). Further purification of this fraction was performed by following the resuspension/ centrifugation technique described above for $\mathbf{1}$ with some modifications. In this case, instead of pursuing another round of flash chromatography, two cycles of resuspension and centrifugation in HPLC-grade $\mathrm{MeOH}$ (12 ml for the 1st
Extracts from the fungal strain MSX63935 grown on rice showed the highest abundance of (5Z)-7-oxozeaenol (2) (Fig. 2) and therefore were used for the isolation studies. By 
cycle and $6 \mathrm{ml}$ for the 2nd cycle) were followed by another two cycles of resuspension and centrifugation in HPLCgrade $\mathrm{CH}_{3} \mathrm{CN}$ ( $6 \mathrm{ml}$ per cycle); each time, the centrifuge time and force was the same as noted for $\mathbf{1}$. In each case, the precipitates were collected, with a final yield of $760 \mathrm{mg}$ of 2 ( $>94 \%$ pure; Fig. S15). The supernatants from the four cycles of centrifugations were collected (i.e., $118 \mathrm{mg}, 57$ $\mathrm{mg}, 39 \mathrm{mg}$, and $75 \mathrm{mg}$, respectively), and their ${ }^{1} \mathrm{H} \mathrm{NMR}$ spectra were compared to that of the precipitate (Fig. S16). As expected, and despite the presence of $\mathbf{2}$ as a main constituent in the supernatant samples, the amount of other secondary metabolites was high. Similar to our experience with 1, the streamlined procedure, which did not require HPLC, was used to generate more than $750 \mathrm{mg}$ of $\mathbf{2}$, which are now being used as feedstock in semi-synthetic chemistry studies, similar to those reported previously [21]. Again, the amount of $\mathbf{2}$ that was "lost" in the supernatant samples

Fig. 5 Fungal secondary metabolites produced by strains MSX78495 and MSX63935<smiles>COC1=CC=C(C(=O)OC(C)CCCC(=O)O)C(C(=O)O)=c2cc(OC)ccc2=C1</smiles>

3<smiles>CO[C@H](C)C/C=C\C(=O)[C@@H](O)[C@H](O)CCC(=O)c1cc(O)cc(O)c1C(=O)O</smiles>

6

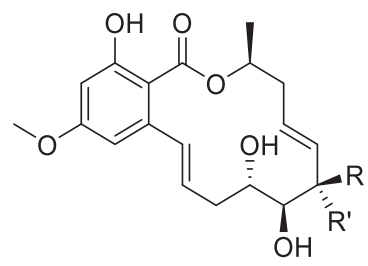

9: $\mathbf{R}=\mathbf{H}, \mathbf{R}^{\prime}=\mathbf{O H}$

10: $\mathbf{R}=\mathbf{O H}, \mathbf{R}^{\prime}=\mathbf{H}$<smiles>CCCc1cc2c(c(=O)o1)C(=O)[C@H](O)[C@H](C)O2</smiles>

was relatively low (i.e., $\sim 138 \mathrm{mg}$ ) and can be recovered by 1-2 injections via prep-HPLC, as described below.

\section{Chemical profile of hypothemycin-producing fungal strain (MSX78495)}

Purification of hypothemycin (1) from cultures of strain MSX78495 required its separation from other metabolites produced by this fungus. To study the other minor constituents, the supernatants were subjected to preparative high-performance liquid chromatography (HPLC) to obtain six RALs. In addition to 1 [44] and 2 [30, 45], dihydrohypothemycin (3) [46], aigialomycin A (4) [46], paecilomycin A (5) [47], and 4-O-demethylhypothemycin (6) [48] were isolated (Fig. 5), and their NMR data compared favourably to literature values (see Figs. S17-S22 for ${ }^{1} \mathrm{H}$ and ${ }^{13} \mathrm{C}$ NMR spectra of 1-6).<smiles>COc1cc(OC)cc([C@@H]2O[C@H]2C[C@H](O)[C@H](O)C(=O)/C=C/C[C@@H](C)OC(=O)c2c(O)cc(OC)cc2O)c1</smiles>

4<smiles>C/C=C/C[C@@H](O)[C@H](O)C(=O)/C=C/C[C@@H](C)OC(=O)c1c(O)cc(OC)cc1O</smiles>

7<smiles>C/C=C/C[C@@H](O)[C@H](O)C(=O)/C=C/C[C@@H](C)OC(=O)c1c(O)cc(OC)cc1O</smiles>

12<smiles>[R2]Oc1cc2c(=O)oc3cc(O)c([R])c(O)c3c2cc1[R]</smiles>

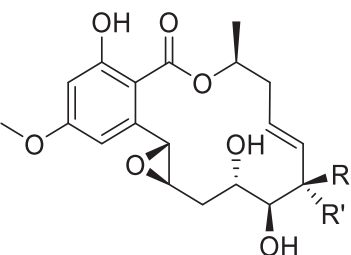

5: $\mathbf{R}=\mathbf{O H}, \mathbf{R}^{\prime}=\mathbf{H}$

11: $R=H, R^{\prime}=O H$<smiles>COc1cc(O)cc(/C=C/C[C@H](O)[C@H](O)C(=O)CCC[C@@H](C)OC(=O)c2c(O)cc(OC)cc2O)c1</smiles>

8

13

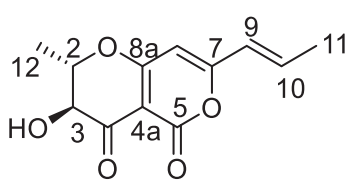

15: $\mathbf{R}_{\mathbf{1}}=\mathbf{R}_{\mathbf{2}}=\mathbf{R}_{\mathbf{3}}=\mathbf{H}$

16: $\mathbf{R}_{1}=\mathbf{C H}_{3}, \mathbf{R}_{2}=\mathbf{R}_{3}=H$

17: $\mathbf{R}_{\mathbf{1}}=\mathbf{R}_{\mathbf{2}}=\mathbf{H}, \mathbf{R}_{\mathbf{3}}=\mathrm{Cl}$

18: $\mathbf{R}_{1}=\mathrm{CH}_{3}, \mathbf{R}_{\mathbf{2}}=\mathrm{H}, \mathbf{R}_{\mathbf{3}}=\mathrm{Cl}$

19: $\mathbf{R}_{1}=\mathrm{CH}_{3}, \mathbf{R}_{2}=\mathrm{Cl}, \mathrm{R}_{\mathbf{3}}=\mathrm{H}$

20: $\mathbf{R}_{1}=\mathrm{CH}_{3}, \mathbf{R}_{2}=\mathbf{R}_{3}=\mathrm{Cl}$ 


\section{Chemical profile of (5Z)-7-oxozeaenol-producing fungal strain (MSX63935)}

The fungal strain MSX63935 exhibited more chemical diversity and higher sensitivity to culture medium as compared to strain MSX78495 (Fig. S5). Investigating the content of the collected supernatant via preparative HPLC showed that strain MSX63935 was producing three classes of fungal secondary metabolites. In addition to the RALs (1-2 and 7-12), two radicinin analogues (13-14) and six benzopyranones (15-20) were isolated (Fig. 5). ${ }^{1} \mathrm{H}$ and ${ }^{13} \mathrm{C}$ NMR data were used for identifying these compounds as hypothemycin (1), (5Z)-7-oxozeaenol (2), (5E)-7-oxozeaenol (7) [30], LL-Z1640-1 (8) [49], zeaenol (9) [50], 7-epizeaenol (10), aigialomycin B (11) [46], cochliomycin F (12) [51], radicinin (13) [52], dihydroradicinin (14) [53], alternariol (15) [54], alternariol 9-methyl ether (16) [55], rhizopycnin D (17) [56], palmariol B (18) [55], and the two new benzopyranones (19-20). ${ }^{1} \mathrm{H}$ and ${ }^{13} \mathrm{C}$ NMR spectra of 7-18 are presented in Figs. S23-S34.

Compound 19 was obtained as a white amorphous powder with HRESIMS data matching that observed for palmariol A and B (18) [55, 57]. The isotopic pattern in the mass spectrum indicated the presence of one chlorine atom in 19, i.e., molecular ion peaks $[\mathrm{M}+\mathrm{H}]^{+}$of $\mathrm{m} / z 307$ and 309 in a 3 to 1 ratio (Fig. S35). The NMR data indicated the presence of twelve aromatic carbons, one carbonyl, an aromatic methyl, a methoxy group, and three aromatic protons (Table 1 and Fig. S36). Two of the aromatic protons

Table $1{ }^{1} \mathrm{H}$ and ${ }^{13} \mathrm{C}$ NMR spectroscopic data for $\mathbf{1 9}$ and $\mathbf{2 0}$ in DMSO- $d_{6}$

\begin{tabular}{lllll}
\hline & $19^{\mathrm{a}}$ & & $20^{\mathrm{b}}$ & \\
\hline Position & $\delta_{\mathrm{C}}$, type & $\delta_{\mathrm{H}}(J, \mathrm{~Hz})$ & $\delta_{\mathrm{C}}$, type & $\delta_{\mathrm{H}}(J, \mathrm{~Hz})$ \\
1 & $138.3, \mathrm{C}$ & & $135.5, \mathrm{C}$ & \\
2 & $118.0, \mathrm{CH}$ & $6.71, \mathrm{~d}(2.3)$ & $120.3, \mathrm{C}$ & \\
3 & $158.9, \mathrm{C}$ & & $155.2, \mathrm{C}$ & \\
4 & $101.6, \mathrm{CH}$ & $6.59, \mathrm{~d}(2.3)$ & $101.9, \mathrm{CH}$ & $6.89, \mathrm{~s}$ \\
$4 \mathrm{a}$ & $152.5, \mathrm{C}$ & & $150.2, \mathrm{C}$ & \\
6 & $164.4, \mathrm{C}$ & & $164.2, \mathrm{C}$ & \\
$6 \mathrm{a}$ & $99.5, \mathrm{C}$ & & $100.3, \mathrm{C}$ & \\
7 & $158.3, \mathrm{C}$ & & $158.1, \mathrm{C}$ & \\
8 & $105.8, \mathrm{C}$ & & $106.4, \mathrm{C}$ & \\
9 & $160.7, \mathrm{C}$ & & $160.7, \mathrm{C}$ & \\
10 & $99.7, \mathrm{CH}$ & $7.23, \mathrm{~s}$ & $101.2, \mathrm{CH}$ & $7.38, \mathrm{~s}$ \\
$10 \mathrm{a}$ & $136.1, \mathrm{C}$ & & $135.5, \mathrm{C}$ & \\
$10 \mathrm{~b}$ & $108.4, \mathrm{C}$ & & $110.1, \mathrm{C}$ & \\
11 & $24.9, \mathrm{CH}_{3}$ & $2.73, \mathrm{~s}$ & $20.9, \mathrm{CH}_{3}$ & $2.92, \mathrm{~s}$ \\
$\mathrm{CH}_{3} \mathrm{O}-9$ & $56.5, \mathrm{CH}_{3}$ & $4.01, \mathrm{~s}$ & $56.9, \mathrm{CH}_{3}$ & $4.09, \mathrm{~s}$ \\
\hline
\end{tabular}

${ }^{\text {a}}$ Recorded at $400 \mathrm{MHz}$ for ${ }^{1} \mathrm{H}$ and $100 \mathrm{MHz}$ for ${ }^{13} \mathrm{C}$

${ }^{\mathrm{b}}$ Recorded at $500 \mathrm{MHz}$ for ${ }^{1} \mathrm{H}$ and $125 \mathrm{MHz}$ for ${ }^{13} \mathrm{C}$ (i.e., $\mathrm{H}-2$ and H-4) showed meta-coupling with a $J$ value of $2.3 \mathrm{~Hz}$ indicating their presence on a tetrasubstituted aromatic ring (Table 1 and Fig. S38). The HMBC correlations of $\mathrm{H}-2$ with $\mathrm{C}-3, \mathrm{C}-4, \mathrm{C}-10 \mathrm{~b}$, and $\mathrm{C}-11$ and $\mathrm{H}-4$ with $\mathrm{C}-2$, $\mathrm{C}-3, \mathrm{C}-4 \mathrm{a}$, and $\mathrm{C}-10 \mathrm{~b}$ confirmed the structure of ring $\mathrm{A}$ (Figs. S39 and S46). The third singlet aromatic signal at $\delta_{\mathrm{H}}$ $7.23(\mathrm{H}-10)$ indicated the presence of a pentasubstituted aromatic ring. The $\mathrm{HMBC}$ correlations of $\mathrm{H}-10$ with $\mathrm{C}-10 \mathrm{a}$ and $\mathrm{C}-10 \mathrm{~b}$ established the connections between ring $\mathrm{A}$ and $\mathrm{C}$ through ring $\mathrm{B}$. The HMBC correlations of the methoxy protons with C-9 and C-10 confirmed its position at C-9 (Figs. S39 and S46). The position of the chlorine atom at C-8 was suggested by the HMBC correlation of $\mathrm{H}-10$ with $\mathrm{C}-8$, in addition to the chemical shift of C-8 $\left(\delta_{\mathrm{C}} 105.8\right)$.

In a similar fashion, the molecular formula of $\mathbf{2 0}$ was deduced by HRESIMS data as $\mathrm{C}_{15} \mathrm{H}_{10} \mathrm{Cl}_{2} \mathrm{O}_{5}$ (Fig. S41). The molecular ion peaks $[\mathrm{M}+\mathrm{H}]^{+}$of $\mathrm{m} / \mathrm{z} 341,343$, and 345 at a 9:6:1 ratio confirmed the presence of two chlorine atoms in 20. The NMR data indicated the presence of two singlet aromatic protons, instead of the three observed in $\mathbf{1 9}$ (Table 1 and Fig. S42). The absence of meta-coupling between these two aromatic protons suggested the position of the second chlorine atom at either $\mathrm{C}-2$ or $\mathrm{C}-4$, and the HMBC correlation of $\mathrm{H}_{3}-11$ with $\mathrm{C}-2$ confirmed the position of the second chlorine atom at C-2 (Figs. S44 and S46).

The relatively small molecular weight of these two benzopyranones (19 and 20), their low hydrogen to carbon ratio, and the sparsity of ${ }^{1} \mathrm{H}-{ }^{1} \mathrm{H}$ coupling imparts difficulty in confirming the positions of the aromatic substituents. Therefore, NOESY experiments were used to further facilitate the structure elucidation of these compounds, and this approach has been implemented for other hydrogendeficient natural products [10]. The NOESY correlations between $\mathrm{H}-2 / \mathrm{CH}_{3}-11, \mathrm{CH}_{3}-11 / \mathrm{H}-10, \mathrm{H}-10 / \mathrm{CH}_{3} \mathrm{O}-9$ confirmed the structure of 19 (Figs. S40 and S47). Similarly, compound 20 showed NOESY correlations between $\mathrm{CH}_{3}-$ $11 / \mathrm{H}-10, \mathrm{H}-10 / \mathrm{CH}_{3} \mathrm{O}-9, \mathrm{CH}_{3} \mathrm{O}-9 / \mathrm{CH}_{3}-11$ suggesting the replacement of the aromatic proton at $\mathrm{C}-2$ with a second chlorine atom (Figs. S45 and S47). The structures of 19 and 20 were similar to palmariol $\mathrm{A}$ and $\mathrm{B}$, which are monochlorinated benzopyranones isolated from Lachnum palmae and Hyalodendriella sp. [55, 57]. Palmariol A has a chlorine attached to $\mathrm{C}-4$, while palmariol $\mathrm{B}$ has a chlorine attached to C-2. Thus, compounds $\mathbf{1 9}$ and 20 were ascribed the trivial names palmariol $\mathrm{C}$ and palmariol $\mathrm{D}$, respectively.

\section{Discussion and conclusion}

Herein, the OSMAC approach was used to enhance the biosynthesis of cis-enone RALs from three different fungal strains. Interestingly, the effect of fermentation media, i.e., rice, oatmeal, and Cheerios, on the production of these 
compounds was different across the three fungal strains. Hypothemycin (1) was detected in the extracts of the three fungal strains (MSX78495, MSX63935, and MSX45109), which agreed with the previously reported isolation of $\mathbf{1}$ from MSX63935 and MSX45109 [30, 31]. However, the yield of $\mathbf{1}$ was significantly higher in fungal strain MSX78495 as compared to the latter two strains (Fig. 2 and S6), and while growth media did not have a large impact on the chemical profile, oatmeal medium allowed for the highest yield of $\mathbf{1}$. Despite the structural similarity between (5Z)-7-oxozeaenol (2) and 1 (i.e., its epoxide derivative), fungal strain MSX63935 was the main producer of $\mathbf{2}$ as compared to strain MSX78495 (Fig. 2 and S6). Moreover, culture media had a significant impact on the biosynthesis of $\mathbf{2}$, where rice medium allowed for a higher yield as compared to oatmeal, while production was nearly eliminated in Cheerios. The effect of fermentation medium on the production of $\mathbf{1}$ from Aigialus parvus was reported previously, where culture medium and its initial $\mathrm{pH}$ were the most important factors that affect the production of $\mathbf{1}$ [58]. However, that study was for growth in liquid media, which yielded $13.6 \mathrm{mg}$ per $\mathrm{g}$ of biomass. In addition, no studies have been reported that optimized the production of $\mathbf{2}$ on the lab scale or compared the production of $\mathbf{1}$ vs 2 .

The isolation of $\mathbf{1}$ and $\mathbf{2}$ and their separation from other secondary metabolites in the culture extracts was another aspect addressed in scaling-up the biosynthesis of these compounds. Our usual isolation protocol involves the fractionation of the defatted culture extract via flash chromatography to obtain three to five fractions, followed by one to three rounds of purification using reverse-phase HPLC $[29,30]$. As is well known to this audience, preparative HPLC has become the main isolation tool of natural products in the last several decades [59], and this obviously works quite well for milligram quantities of secondary metabolites. However, its application in gramscale isolation can be challenging and resource intensive, and with $\mathbf{1}$ and 2, scaling their purification via HPLC is limited by the low solubility of these compounds. For example, HPLC can be used to isolate $\mathbf{1}$ and $\mathbf{2}$, but the coelution of dihydrohypothemycin (3) with 1 and LL-Z1640-1 (8) with 2 became problematic when injecting a 50-100 $\mathrm{mg}$ sample (Figs. S48 and S49). Accordingly, using a reversephase HPLC system for the purification of gram quantities of $\mathbf{1}$ and $\mathbf{2}$ would require 10 to 15 repeated cycles of prepHPLC, which would consume large quantities of organic solvents and produce larger amounts of mixed solvent waste. This is in addition to the long extract-to-purification period, personnel and instrumentation time, and the associated high cost of this procedure (Table S4). A simplified purification process was achieved by optimizing the separation method at an early stage via flash chromatography and applying the concept of resuspension and precipitate collection from small solvent volumes. The facts that $\mathbf{1}$ and $\mathbf{2}$ were the main constituents in the original extracts, and that both exhibit relatively low solubility in solvents like $\mathrm{MeOH}$ and $\mathrm{CH}_{3} \mathrm{CN}$, allowed for the enrichment of these two compounds by sedimentation in a sub-gram to gram quantity (Figs. 3 and 4). As evidenced by the composition of the secondary metabolites isolated from the collected supernatants (Fig. 5), two to four cycles of resuspension/precipitate collection were efficient for purifying the targeted two cis-enone RALs from a mixture that includes compounds from the same structural class and/or other different classes. Table $\mathrm{S} 4$ compares the application of reverse-phase HPLC vs. the resuspension/centrifugation technique in the purification of $\mathbf{1}$ and $\mathbf{2}$. Moreover, the ultimate goal is to use $\mathbf{1}$ and $\mathbf{2}$ as feedstock for semisynthetic efforts, as will be reported in the future, and thus, having a larger quantity (i.e., gram-scale) was more important than the final purity, since synthesis products will be purified in the final step.

In conclusion, cis-enone RALs are fungal metabolites with promising activities that could be explored as anticancer drug leads. Scaling up the production of these compounds from the milligram to gram scale required the identification of the best producing fungal strain, modifying fungal growth conditions to enhance their biosynthesis, and the implementation of practical and time efficient purification techniques. Applying the above three-pronged approach allowed for the isolation of $1043 \mathrm{mg}$ of hypothemycin (1), $760 \mathrm{mg}$ of (5Z)-7-oxozeaenol (2), and the identification of 18 (1-18) known and two new (19-20) secondary metabolites.

\section{Materials and methods}

\section{General experimental procedures}

Ultraviolet (UV) spectra were measured using a Varian Cary 100 Bio UV-Vis spectrophotometer (Varian Inc.). 1D and 2D NMR data were obtained using a JEOL ECA-500 spectrometer operating at $500 \mathrm{MHz}$ or a JEOL ECS-400 spectrometer operating at $400 \mathrm{MHz}$ that is equipped with a high sensitivity JEOL Royal probe and a 24-slot autosampler (both from JEOL Ltd.). Residual solvent signals were utilized for referencing (for $\mathrm{CDCl}_{3} \delta_{\mathrm{H}} / \delta_{\mathrm{C}} 7.26 / 77.16$ and for DMSO- $\left.d_{6} \delta_{\mathrm{H}} / \delta_{\mathrm{C}} 2.50 / 39.52\right)$. UPLC-HRESIMS data were collected via an LTQ-Orbitrap XL mass spectrometer (Thermo Finnigan, San Jose, CA, USA) equipped with an electrospray ionization source (ESI) and connected to a Waters Acquity UPLC system. A BEH Shield RP18 column (Waters, $1.7 \mu \mathrm{m} ; 50 \times 2.1 \mathrm{~mm}$ ) was used and heated to $40^{\circ} \mathrm{C}$. The flow rate of the mobile phase was $0.3 \mathrm{ml} \mathrm{min}^{-1}$ and consisted of a gradient system of $15: 85$ to $100: 0$ of 
$\mathrm{CH}_{3} \mathrm{CN}-\mathrm{H}_{2} \mathrm{O}(0.1 \%$ formic acid $)$ over $10 \mathrm{~min}$. MS data were collected from $\mathrm{m} / \mathrm{z} 150$ to 2000 in the positive mode. A Varian Prostar HPLC system, equipped with ProStar 210 pumps and a Prostar 335 photodiode array detector (PDA), was used to conduct all analytical and preparative HPLC experiments, with data collected and analyzed using Galaxie Chromatography Workstation software (version 1.9.3.2, Varian Inc.). Flash chromatography was performed on a Teledyne ISCO CombiFlash Rf 200 using Silica Gold columns (from Teledyne Isco) and monitored by UV and evaporative light-scattering detectors. An Eppendorf 5415 centrifuge, equipped with rotor F-45-18-11, was used for the resuspension/centrifugation of fractions enriched in hypothemycin (1) and (5Z)-7-oxozeaenol (2).

\section{Fungal strains identification}

Mycosynthetix fungal strain MSX45109 was isolated from leaf litter collected in a mangrove habitat in 1989 [31]; MSX63935 was isolated in 1992 from leaf litter collected at an agricultural farm [30]; and MSX78495 was collected on terrestrial leaf litter in 1993 in a semi humid gallery forest. These three strains were isolated by Dr. Barry Katz. Molecular techniques were used to identify the three strains by sequencing the internal transcribed spacer regions $1 \& 2$ and $5.8 \mathrm{~S}$ nrDNA (ITS) $[60,61]$ with primers ITS1F and ITS4 [62, 63]. As MSX45109 was identified in a previous study as Setophoma terrestris [31], we hypothesized that the two other RAL producing strains may have phylogenetic affinities to Setophoma. A BLAST search using the RefSeq Database in NCBI GenBank showed that strains MSX63935 and MSX78495 had $\geq 90 \%$ sequence homology with members of Setophoma spp. [64]. Hence, we downloaded all previously described species of Setophoma from recently published literature [65-69] and constructed a multiple sequence alignment in MUSCLE using the program Seaview [70]. The alignment was trimmed to remove ambiguous characters using GBlocks [71]. ModelFinder was used to select the best-fit model using Akaike Information Criterion [72]. The best fitting substitution model: transversion model with empirical base frequencies, allowing for a proportion of invariable sites, and a discrete Gamma model with four rate categories (TVM $+\mathrm{F}+\mathrm{I}+$ G4) was determined by AIC. The trimmed alignment was then used to infer the Maximum Likelihood of ITS sequence data using IQ-TREE implemented in PhyloSuite [73]. Ultrafast bootstrapping was done with 5000 replicates [74]. Nodes with UFBoot $\geq 90 \%$ are shown on the clades but only nodes $\geq 95 \%$ were considered strongly supported. Based on results of the Maximum Likelihood analysis using IQ-Tree, the MSX strains showed phylogenetic affinities with Setophoma and were nested within the Setophoma clade (Fig. S50), but we could not assign a species name to strains MSX63935 and MSX78495. It is likely these two strains represent putative new isolates; however additional phenotypic data along with multigene data from LSU, $t u b 2$, tef- $1 \alpha$ and gapdh (i.e., a polyphasic approach) needs to be undertaken to determine their exact identities. Herein, we identify the two strains as Setophoma spp. (Phaeosphaeriaceae, Pleosporales Ascomycota). The ITS sequences of the two new strains were deposited in the GenBank (accession numbers: MSX63935: MW881143, MW881144; MSX78495: MW881145, MW881146).

\section{Media and fermentations}

The cultures of fungal strains MSX78495, MSX63935, and MSX45109 were maintained on potato dextrose agar (PDA; Difco) and were transferred periodically to fresh PDA plates. An agar plug from the leading edge of the PDA culture was transferred to a sterile tube with $10 \mathrm{ml}$ of YESD ( $2 \%$ soy peptone, $2 \%$ dextrose, and $1 \%$ yeast extract). The YESD culture was grown for 7 days on an orbital shaker $(100 \mathrm{rpm})$ at room temperature $\left(\sim 23^{\circ} \mathrm{C}\right)$ and then used to inoculate three types of solid fermentation media.

As previously described [4], cultures of each fungal strain were grown in three different grain-based media in triplicate: rice, breakfast oatmeal, and Cheerios breakfast cereal [75] for a total of 27 cultures (Fig. S2 and S3). Solidstate fermentations were carried out in 250-ml Erlenmeyer flasks. To prepare rice medium, $10 \mathrm{~g}$ of rice were added to each flask with $20 \mathrm{ml}$ of deionized water (DI $\mathrm{H}_{2} \mathrm{O}$ ). For the oatmeal medium, the same amount was used in each flask with $17 \mathrm{ml}$ of DI $\mathrm{H}_{2} \mathrm{O}$. For Cheerios medium, $7 \mathrm{~g}$ of Cheerios were used in each flask without water. After autoclaving these samples at $120^{\circ} \mathrm{C}$ for $20 \mathrm{~min}$, the flasks were inoculated with YESD seed cultures (described above) and incubated at room temperature for 2 weeks. Over the incubation period, the fungal cultures grew normally with no sign of growth retardation, except for the MSX63935 cultures growing on Cheerios medium, which were dried out by the time of extraction (Fig. S3).

\section{Extraction, fractionation, and isolation}

The extraction procedure was described previously [4]. Briefly, each flask of solid culture was extracted with $90 \mathrm{ml}$ of 1:2 $\mathrm{CH}_{3} \mathrm{OH}-\mathrm{CHCl}_{3}$ and vacuum filtered. To the filtrate, $90 \mathrm{ml}$ of $\mathrm{CHCl}_{3}$ and $100 \mathrm{ml}$ of $\mathrm{DI} \mathrm{H}_{2} \mathrm{O}$ were added, and the mixture was stirred for $30 \mathrm{~min}$ and then transferred into a separatory funnel. The bottom layer was drawn off and evaporated to dryness. The dried organic extract was reconstituted in $100 \mathrm{ml}$ of $1: 1 \mathrm{CH}_{3} \mathrm{OH}-\mathrm{CH}_{3} \mathrm{CN}$ and $100 \mathrm{ml}$ of hexanes. The $\mathrm{CH}_{3} \mathrm{OH} / \mathrm{CH}_{3} \mathrm{CN}$ layer was drawn off and 
evaporated to dryness under vacuum. The extract amounts that were produced by each culture are shown in Fig. S4. Before performing further fractionation, quantitative UPLCHRESIMS data were collected. After that, the extracts of MSX78495 grown on various media were combined to give a total of $2.4 \mathrm{~g}$ of extract material, while the extracts of MSX63935 grown on rice were combined to provide $1.34 \mathrm{~g}$ of extract material. Both extracts from the fungal strains MSX78495 and MSX63935 were subjected to normalphase flash chromatography to obtain six fractions each using a gradient solvent system of hexanes- $\mathrm{CHCl}_{3}-\mathrm{CH}_{3} \mathrm{OH}$ at a $35 \mathrm{ml} \mathrm{min}^{-1}$ flow rate. The hypothemycin-containing fraction (from MSX78495) and the (5Z)-7-oxozeaenolcontaining fraction (from MSX63935) were identified via UPLC-HRESIMS. Further purification of $\mathbf{1}$ and $\mathbf{2}$ was achieved by following the outlined work-flows (Figs. 3 and 4 , respectively). The supernatant collected from the resuspension/centrifugation process of the hypothemycincontaining fraction (Fig. 3) was subjected to preparative HPLC over a Phenomenex Synergi-Max $\mathrm{C}_{12}$ preparative column using an isocratic system of 35:65 of $\mathrm{CH}_{3} \mathrm{CN}-\mathrm{H}_{2} \mathrm{O}$ ( $0.1 \%$ formic acid) for $30 \mathrm{~min}$ at a flow rate of $21.2 \mathrm{ml} \mathrm{min}^{-1}$ to yield compounds $\mathbf{1}(60 \mathrm{mg}), \mathbf{2}(2.4 \mathrm{mg}), \mathbf{3}(6.0 \mathrm{mg}), \mathbf{4}$ $(5.6 \mathrm{mg}), \mathbf{5}(5.2 \mathrm{mg}), \mathbf{6}(1.6 \mathrm{mg})$. The supernatant collected from the resuspension/centrifugation of the (5Z)-7-oxozeaenol-containing fraction (Fig. 4) was subjected to preparative HPLC over a Phenomenex Synergi-Max $\mathrm{C}_{12}$ preparative column using an isocratic system of 35:65 of $\mathrm{CH}_{3} \mathrm{CN}-\mathrm{H}_{2} \mathrm{O}$ ( $0.1 \%$ formic acid) for $28 \mathrm{~min}$, then to $80: 20$ of $\mathrm{CH}_{3} \mathrm{CN}-\mathrm{H}_{2} \mathrm{O}$ (0.1\% formic acid) over $5 \mathrm{~min}$ at a flow rate of $21.2 \mathrm{~mL} / \mathrm{min}$ to yield compounds $\mathbf{1}(1.1 \mathrm{mg})$, 2 (137.9 mg), 7 (27.2 mg), 8 (10.0 mg), 9 (7.7 mg), $10(2.1 \mathrm{mg}), \mathbf{1 1}(2.45 \mathrm{mg}), \mathbf{1 2}(1.9 \mathrm{mg}), \mathbf{1 3}(3.0 \mathrm{mg})$, $14(1.4 \mathrm{mg}), \mathbf{1 5}(8.2 \mathrm{mg}), \mathbf{1 6}(4.0 \mathrm{mg}), \mathbf{1 7}(2.4 \mathrm{mg}), \mathbf{1 8}$ (2.0 mg), 19 (13.7 mg), 20 (1.9 mg).

\section{Palmariol C (19)}

Compound 19 was isolated as a white amorphous powder, m.p. $>260^{\circ} \mathrm{C}$ with signs of decomposition; UV $\left(\mathrm{CH}_{3} \mathrm{OH}\right)$ $\lambda_{\max }(\log \varepsilon) 205$ (4.2), 257 (4.5), 291 (3.9), 302 (3.9), 342 (3.9) $\mathrm{nm}$; IR $\mathrm{v}_{\max } 3483,2973,2266,1654,1608,1580$, $1550,1493,1449,1430,1403 \mathrm{~cm}^{-1} ;{ }^{1} \mathrm{H}$ NMR (DMSO- $d_{6}$, $400 \mathrm{MHz}$ ) and ${ }^{13} \mathrm{C}$ NMR (DMSO- $d_{6}, 100 \mathrm{MHz}$ ) (see Table 1); HRESIMS $\mathrm{m} / \mathrm{z}, 307.0364[\mathrm{M}+\mathrm{H}]^{+}$(calcd. for $\left.\mathrm{C}_{15} \mathrm{H}_{12} \mathrm{ClO}_{5}, 307.0373\right)$.

\section{Palmariol D (20)}

Compound $\mathbf{2 0}$ was isolated as a white amorphous powder, m.p. $>260{ }^{\circ} \mathrm{C}$ with signs of decomposition; UV $\left(\mathrm{CH}_{3} \mathrm{OH}\right)$ $\lambda_{\max }(\log \varepsilon) 212$ (4.0), 299 (3.7), 258 (4.0), 347 (4.0) nm; IR $\mathrm{v}_{\max } 3300,2924,1650,1598,1582,1546,1509,1463$, $1425 \mathrm{~cm}^{-1} ;{ }^{1} \mathrm{H}$ NMR (DMSO- $d_{6}, 500 \mathrm{MHz}$ ) and ${ }^{13} \mathrm{C}$ NMR (DMSO- $d_{6}, 125 \mathrm{MHz}$ ) (see Table 1); HRESIMS $\mathrm{m} / \mathrm{z}$ $340.9974[\mathrm{M}+\mathrm{H}]^{+}$(calcd. for $\mathrm{C}_{15} \mathrm{H}_{11} \mathrm{Cl}_{2} \mathrm{O}_{5}, 340.9984$ ).

\section{Quantification of hypothemycin (1) and (5Z)-7- oxozeaenol (2)}

Calibration curves of hypothemycin (1) and (5Z)-7-oxozeaenol (2) were developed using pure standards isolated from fungal strains MSX78495 and MSX63935, respectively. Ten standard solutions were prepared in $\mathrm{CH}_{3} \mathrm{CN}$ at a concentration range of $3-1536 \mathrm{ng} \mathrm{ml}^{-1}$. HRESIMS data were collected in triplicate via a UPLC-HRESIMS (Thermo LTQ Orbitrap XL) system using the area under the curve (AUC) to generate the calibration curves. A BEH Shield RP18 column (Waters, $1.7 \mu \mathrm{m} ; 50 \times 2.1 \mathrm{~mm}$ ) heated to $40{ }^{\circ} \mathrm{C}$ was utilized with a flow rate of the mobile phase of $0.3 \mathrm{ml} \mathrm{min}^{-1}$ and a gradient system of 15:85 to 100:0 of $\mathrm{CH}_{3} \mathrm{CN}-\mathrm{H}_{2} \mathrm{O}$ ( $0.1 \%$ formic acid) over $10 \mathrm{~min}$. MS data were collected from $\mathrm{m} / \mathrm{z}, 150$ to 2000 in the positive mode. The linearity of each calibration curve, relative error (RE), and limit of quantitation (LOQ), which is the lowest amount of analyte that can be quantitatively determined with suitable precision and accuracy, were calculated and summarized (Fig. S7 and Table S3). Extracts from the fungal strains MSX78495, MSX63935, and MSX45109 were analyzed in triplicate, the areas were averaged, and the concentrations of $\mathbf{1}$ and $\mathbf{2}$ were extrapolated from the corresponding calibration curve. Statistical analysis was carried out using GraphPad Prism (GraphPad Software, La Jolla, CA), and comparisons were made using one-way ANOVA followed by Tukey post hoc test.

\section{Data availability}

Images of the three cis-enone RALs-producing fungi on different solid-state growth conditions, the extract amounts produced by these fungi, the UPLC chromatograms of culture extracts, calibration curves of hypothemycin and (5Z)-7-oxozeaenol, flash chromatography chromatogram of the extracts, H NMR spectra and UPLC purity of hypothemycin- and (5Z)-7-oxozeaenol-containing fractions, $\mathrm{H}$ NMR spectra of compounds 1-18, and 1D and 2D NMR spectra of compounds 19 and 20. The raw NMR spectra for 1-20 were deposited in Harvard Dataverse and can be freely accessed through https://doi.org/10.7910/DVN/XUQPLU.

Acknowledgements This research was supported in part by the National Institutes of Health via the National Cancer Institute through grants P01 CA125066 and R15 CA246491 and via the National Institute of General Medical Sciences through grant T34 GM113860. 


\section{Compliance with ethical standards}

Conflict of interest The authors declare the following competing financial interest(s): NHO is a member of the Scientific Advisory Board of Mycosynthetix, Inc.

Publisher's note Springer Nature remains neutral with regard to jurisdictional claims in published maps and institutional affiliations.

Open Access This article is licensed under a Creative Commons Attribution 4.0 International License, which permits use, sharing, adaptation, distribution and reproduction in any medium or format, as long as you give appropriate credit to the original author(s) and the source, provide a link to the Creative Commons license, and indicate if changes were made. The images or other third party material in this article are included in the article's Creative Commons license, unless indicated otherwise in a credit line to the material. If material is not included in the article's Creative Commons license and your intended use is not permitted by statutory regulation or exceeds the permitted use, you will need to obtain permission directly from the copyright holder. To view a copy of this license, visit http://creativecommons. org/licenses/by/4.0/.

\section{References}

1. Hawksworth DL, Lücking R. Fungal diversity revisited: 2.2 to 3.8 million species. Microbiol Spectr. 2017;5:FUNK-0052-2016.

2. Blackwell M. The fungi: 1, 2, 3.. 5.1 million species? Am J Bot. 2011;98:426-38.

3. Pan R, Bai X, Chen J, Zhang H, Wang H. Exploring structural diversity of microbe secondary metabolites using OSMAC strategy: a literature review. Front Microbiol. 2019;10:294.

4. Al Subeh ZY, Raja HA, Monro S, Flores-Bocanegra L, El-Elimat T, Pearce CJ, et al. Enhanced production and anticancer roperties of photoactivated perylenequinones. J Nat Prod. 2020;83:2490-500.

5. Höfs R, Walker M, Zeeck A. Hexacyclinic acid, a polyketide from Streptomyces with a novel carbon skeleton. Angew Chem Int Ed Engl. 2000;39:3258-61.

6. Amrine CSM, Raja HA, Darveaux BA, Pearce CJ, Oberlies NH. Media studies to enhance the production of verticillins facilitated by in situ chemical analysis. J Ind Microbiol Biotechnol. 2018;45:1053-65.

7. Sica VP, Figueroa M, Raja HA, El-Elimat T, Darveaux BA, Pearce $\mathrm{CJ}$, et al. Optimizing production and evaluating biosynthesis in situ of a herbicidal compound, mevalocidin, from Coniolariella sp. J Ind Microbiol Biotechnol. 2016;43:1149-57.

8. Vandermolen KM, Darveaux BA, Chen WL, Swanson SM, Pearce CJ, Oberlies NH. Epigenetic manipulation of a filamentous fungus by the proteasome-inhibitor bortezomib induces the production of an additional secondary metabolite. RSC Adv. 2014; 4:18329-35.

9. Graf TN, Kao D, Rivera-Chávez J, Gallagher JM, Raja HA, Oberlies NH. Drug leads from endophytic fungi: Lessons learned via scaled production. Planta Med. 2020;86:988-96.

10. Al Subeh ZY, Raja HA, Maldonado A, Burdette JE, Pearce CJ, Oberlies NH. Thielavins: tuned biosynthesis and LR-HSQMBC for structure elucidation. J Antibiot. 2021;74:300-6.

11. Bode HB, Bethe B, Höfs R, Zeeck A. Big effects from small changes: possible ways to explore nature's chemical diversity. Chembiochem. 2002;3:619-27.

12. Amrine CSM, Huntsman AC, Doyle MG, Burdette JE, Pearce CJ, Fuchs JR, et al. Semisynthetic derivatives of the verticillin class of natural products through acylation of the $\mathrm{C} 11$ hydroxy group. ACS Med Chem Lett. 2021;12:625-30.
13. Shen W, Mao H, Huang Q, Dong J. Benzenediol lactones: a class of fungal metabolites with diverse structural features and biological activities. Eur J Med Chem. 2015;97:747-77.

14. Jana N, Nanda S. Resorcylic acid lactones (RALs) and their structural congeners: Recent advances in their biosynthesis, chemical synthesis and biology. New J Chem. 2018;42:17803-73.

15. Gao Y, Duan FF, Liu L, Peng XG, Meng XG, Ruan HL. Hypothemycin-type resorcylic acid lactones with immunosuppressive activities from a Podospora sp. J Nat Prod. 2021;84: 483-94.

16. Tanaka H, Nishida K, Sugita K, Yoshioka T. Antitumor efficacy of hypothemycin, a new Ras-signaling inhibitor. Jpn J Cancer Res. 1999;90:1139-45.

17. Schirmer A, Kennedy J, Murli S, Reid R, Santi DV. Targeted covalent inactivation of protein kinases by resorcylic acid lactone polyketides. Proc Natl Acad Sci. 2006;103:4234-9.

18. Ninomiya-Tsuji J, Kajino T, Ono K, Ohtomo T, Matsumoto M, Shiina M, et al. A Resorcylic acid lactone, 5Z-7-Oxozeaenol, prevents inflammation by inhibiting the catalytic activity of TAK1 MAPK kinase kinase. J Biol Chem. 2003;278:18485-90.

19. Wu J, Powell F, Larsen NA, Lai Z, Byth KF, Read J, et al. Mechanism and in vitro pharmacology of TAK1 inhibition by (5Z)-7-Oxozeaenol. ACS Chem Biol. 2013;8:643-50.

20. Liu Q, Sabnis Y, Zhao Z, Zhang T, Buhrlage SJ, Jones LH, et al. Developing irreversible inhibitors of the protein kinase cysteinome. Chem Biol. 2013;20:146-59.

21. Fakhouri L, El-Elimat T, Hurst DP, Reggio PH, Pearce CJ, Oberlies $\mathrm{NH}$, et al. Isolation, semisynthesis, covalent docking and transforming growth factor beta-activated kinase 1 (TAK1)-inhibitory activities of (5Z)-7-oxozeaenol analogues. Bioorg Med Chem. 2015;23:6993-9.

22. Napolitano C, Natoni A, Santocanale C, Evensen L, Lorens JB, Murphy PV. Isosteric replacement of the $Z$-enone with haloethyl ketone and $E$-enone in a resorcylic acid lactone series and biological evaluation. Bioorg Med Chem Lett. 2011;21:1167-70.

23. Liniger M, Neuhaus C, Hofmann T, Fransioli-Ignazio L, Jordi M, Drueckes $\mathrm{P}$, et al. Kinase inhibition by deoxy analogues of the resorcylic lactone L-783277. ACS Med Chem Lett. 2010;2:22-7.

24. Jogireddy R, Barluenga S, Winssinger N. Molecular editing of kinase-targeting resorcylic acid lactones (RAL): Fluoroenone RAL. ChemMedChem 2010;5:670-3.

25. Hearn B, Sundermann K, Cannoy J, Santi D. Semisynthesis and cytotoxicity of hypothemycin analogues. ChemMedChem 2007;2:1598-600.

26. Althagafy HS, Graf TN, Sy-Cordero AA, Gufford BT, Paine MF, Wagoner J, et al. Semisynthesis, cytotoxicity, antiviral activity, and drug interaction liability of 7-O-methylated analogues of flavonolignans from milk thistle. Bioorg Med Chem. 2013;21: 3919-26.

27. Paguigan ND, Al-Huniti MH, Raja HA, Czarnecki A, Burdette JE, González-Medina M, et al. Chemoselective fluorination and chemoinformatic analysis of griseofulvin: Natural vs fluorinated fungal metabolites. Bioorg Med Chem. 2017;25:5238-46.

28. Al-Huniti MH, Rivera-Chávez J, Colón KL, Stanley JL, Burdette JE, Pearce CJ, et al. Development and utilization of a palladium-catalyzed dehydration of primary amides to form nitriles. Org Lett. 2018;20:6046-50.

29. El-Elimat T, Raja HA, Day CS, Chen WL, Swanson SM, Oberlies NH. Greensporones: resorcylic acid lactones from an aquatic Halenospora sp. J Nat Prod. 2014;77:2088-98.

30. Ayers S, Graf TN, Adcock AF, Kroll DJ, Matthew S, Carcache de Blanco EJ, et al. Resorcylic acid lactones with cytotoxic and NF-B inhibitory activities and their structure-activity relationships. J Nat Prod. 2011;74:1126-31.

31. El-Elimat T, Figueroa M, Raja HA, Graf TN, Swanson SM, Falkinham JO, et al. Biosynthetically distinct cytotoxic 
polyketides from Setophoma terrestris. Eur J Org Chem. 2015; 2015:109-21.

32. Acuña UM, Wittwer J, Ayers S, Pearce CJ, Oberlies NH, DE Blanco EJ. Effects of (5Z)-7-oxozeaenol on the oxidative pathway of cancer cells. Anticancer Res. 2012;32:2665-71.

33. AcuÑA UM, Wittwer J, Ayers S, Pearce CJ, Oberlies NH, DE Blanco EJ. Effects of (5Z)-7-oxozeaenol on MDA-MB-231 breast cancer cells. Anticancer Res. 2012;32:2415-21.

34. Janecki T, editor. Natural lactones and lactams: synthesis, occurrence and biological activity. Wiley-VCH Verlag GmbH \& Co. KGaA; 2013.

35. Dakas PY, Jogireddy R, Valot G, Barluenga S, Winssinger N. Divergent syntheses of resorcylic acid lactones: L-783277, LLZ1640-2, and hypothemycin. Chemistry. 2009;15:11490-7.

36. Majhi S, Das D. Chemical derivatization of natural products: semisynthesis and pharmacological aspects- A decade update. Tetrahedron. 2021;78:131801.

37. Yñigez-Gutierrez AE, Bachmann BO. Fixing the unfixable: the art of optimizing natural products for human medicine. J Med Chem. 2019;62:8412-28.

38. Truax NJ, Romo D. Bridging the gap between natural product synthesis and drug discovery. Nat Prod Rep. 2020;37:1436-53.

39. Schwan J, Christmann M. Enabling strategies for step efficient syntheses. Chem Soc Rev. 2018;47:7985-95.

40. Wender PA, Verma VA, Paxton TJ, Pillow TH. Function-oriented synthesis, step economy, and drug design. Acc Chem Res. 2008;41:40-9.

41. Sigma-Aldrich: Analytical, Biology, Chemistry \& Materials, 2021.

42. El-Elimat T, Figueroa M, Ehrmann BM, Cech NB, Pearce CJ, Oberlies NH. A high-resolution MS, MS/MS, and UV database of fungal secondary metabolites as a dereplication protocol for bioactive natural products. J Nat Prod. 2013;76:1709-16.

43. Paguigan ND, El-Elimat T, Kao D, Raja HA, Pearce CJ, Oberlies $\mathrm{NH}$. Enhanced dereplication of fungal cultures via use of mass defect filtering. J Antibiot. 2017;70:553-61.

44. Agatsuma T, Takahashi A, Kabuto C, Nozoe S. Revised structure and stereochemistry of hypothemycin. Chem Pharm Bull (Tokyo). 1993;41:373.

45. Tatsuta K, Takano S, Sato T, Nakano S. The first total synthesis of a macrocyclic anti-protozoan, LL-Z1640-2. Chem Lett. 2001;30: $172-3$.

46. Isaka M, Suyarnsestakorn C, Tanticharoen M, Kongsaeree P, Thebtaranonth Y, Aigialomycins A-E. new resorcylic macrolides from the marine mangrove fungus Aigialus parvus. J Org Chem. 2002;67:1561-6.

47. Xu L, He Z, Xue J, Chen X, Wei X. $\beta$-resorcylic acid lactones from a Paecilomyces fungus. J Nat Prod. 2010;73:885-9.

48. Wee JL, Sundermann K, Licari P, Galazzo J. Cytotoxic hypothemycin analogues from Hypomyces subiculosus. J Nat Prod. 2006;69:1456-9.

49. Sugawara F, Kim KW, Kobayashi K, Uzawa J, Yoshida S, Murofushi N, et al. Zearalenone derivatives produced by the fungus Drechslera portulacae. Phytochemistry 1992;31: 1987-90.

50. Jana N, Nanda S. Asymmetric total syntheses of cochliomycin A and zeaenol. Eur J Org Chem. 2012;2012:4313-20.

51. Liu QA, Shao CL, Gu YC, Blum M, Gan LS, Wang KL, et al. Antifouling and fungicidal resorcylic acid lactones from the sea anemone-derived fungus cochliobolus lunatus. J Agric Food Chem. 2014;62:3183-91.

52. Nakajima $H$, Ishida $T$, Otsuka $Y$, Hamasaki $T$, Ichinoe $M$. Phytotoxins and related metabolites produced by Bipolaris coicis, the pathogen of job's tears. Phytochemistry. 1997;45:41-5.
53. Aldrich TJ, Rolshausen PE, Roper MC, Reader JM, Steinhaus MJ, Rapicavoli J, et al. Radicinin from Cochliobolus sp. inhibits Xylella fastidiosa, the causal agent of Pierces Disease of grapevine. Phytochemistry. 2015;116:130-7.

54. Stinson EE, Wise WB, Moreau RA, Jurewicz AJ, Pfeffer PE. Alternariol: evidence for biosynthesis via norlichexanthone. Can J Chem. 1986;64:1590-4.

55. Meng X, Mao Z, Lou J, Xu L, Zhong L, Peng Y, et al. Benzopyranones from the endophytic fungus Hyalodendriella sp. Ponipodef12 and their bioactivities. Molecules. 2012;17:11303-14.

56. Lai D, Wang A, Cao Y, Zhou K, Mao Z, Dong X, et al. Bioactive dibenzo-a-pyrone derivatives from the endophytic fungus Rhizopycnis vagum Nitaf22. J Nat Prod. 2016;79:2022-31.

57. Shigemori H, Hosoya T, Matsumoto T. Palmariols A and B, two new chlorinated dibenzo-a-pyrones from Discomycete Lachnum palmae. Heterocycles. 2010;81:1231.

58. Kocharin K, Supothina S, Prathumpa W. Hypothemycin production and its derivatives diversifying of Aigialus parvus BCC 5311 influenced by cultural condition. Adv Biosci Biotechnol. 2013;04:1049-56.

59. Latif Z, Sarker SD. Isolation of natural products by preparative high performance liquid chromatography (prep-HPLC). Methods Mol Biol. 2012;864:255-74.

60. Schoch CL, Seifert KA, Huhndorf S, Robert V, Spouge JL, Levesque CA, et al. Nuclear ribosomal internal transcribed spacer (ITS) region as a universal DNA barcode marker for Fungi. Proc Natl Acad Sci USA. 2012;109:6241-6.

61. Raja HA, Miller AN, Pearce CJ, Oberlies NH. Fungal identification using molecular tools: a primer for the natural products research community. J Nat Prod. 2017;80:756-70.

62. Gardes M, White TJ, Fortin JA, Bruns TD, Taylor JW. Identification of indigenous and introduced symbiotic fungi in ectomycorrhizae by amplification of nuclear and mitochondrial ribosomal DNA. Can J Bot. 1991;69:180-90.

63. White TJ, Bruns T, Lee SH, Taylor JW. PCR protocols: a guide to methods and application: San Diego. 1991.

64. Schoch CL, Robbertse B, Robert V, Vu D, Cardinali G, Irinyi L, et al. Finding needles in haystacks: linking scientific names, reference specimens and molecular data for Fungi. Database (Oxf). 2014;2014:bau061.

65. Marin-Felix Y, Hernández-Restrepo M, Iturrieta-González I, García D, Gené J, Groenewald JZ, et al. Genera of phytopathogenic fungi: GOPHY 3. Stud Mycol. 2019;94:1-124.

66. Liu F, Wang J, Li H, Wang W, Cai L. Setophoma spp. on Camellia sinensis. Fungal Syst Evol. 2019;4:43-57.

67. Phookamsak R, Liu JK, Manamgoda DS, Chukeatirote E, Mortimer PE, Mckenzie EHC, et al. The sexual state of Setophoma. Phytotaxa. 2014;176:260-9.

68. Quaedvlieg W, Verkley GJ, Shin HD, Barreto RW, Alfenas AC, Swart WJ, et al. Sizing up Septoria. Stud Mycol. 2013;75: 307-90.

69. de Gruyter J, Woudenberg JH, Aveskamp MM, Verkley GJ, Groenewald JZ, Crous PW. Systematic reappraisal of species in Phoma section Paraphoma, Pyrenochaeta and Pleurophoma. Mycologia. 2010;102:1066-81.

70. Gouy M, Guindon S, Gascuel O. SeaView version 4: A multiplatform graphical user interface for sequence alignment and phylogenetic tree building. Mol Biol Evol. 2010;27:221-4.

71. Talavera G, Castresana J. Improvement of phylogenies after removing divergent and ambiguously aligned blocks from protein sequence alignments. Syst Biol. 2007;56:564-77.

72. Kalyaanamoorthy S, Minh BQ, Wong TKF, von Haeseler A, Jermiin LS. ModelFinder: fast model selection for accurate phylogenetic estimates. Nat Methods. 2017;14:587-9. 
73. Zhang D, Gao F, Jakovlić I, Zou H, Zhang J, Li WX, et al. PhyloSuite: an integrated and scalable desktop platform for streamlined molecular sequence data management and evolutionary phylogenetics studies. Mol Ecol Resour. 2020;20:348-55.

74. Nguyen L-T, Schmidt HA, Von Haeseler A, Minh BQ. IQTREE: a fast and effective stochastic algorithm for estimating maximum-likelihood phylogenies. Mol Biol Evol. 2015;32: 268-74.

75. Du L, King JB, Cichewicz RH. Chlorinated polyketide obtained from a Daldinia sp. treated with the epigenetic modifier suberoylanilide hydroxamic acid. J Nat Prod. 2014;77:2454-8. 